\title{
Compliance with the Municipal Agro- Environmental Legislation in Francisco de Orellana, Ecuador
}

\section{Cumplimiento de la Legislación Agroambi- ental Municipal en Francisco de Orellana, Ecuador}

\author{
E. Pozo ${ }^{1}$, J. Pozo², A. Bonilla1, and J. Jimenez ${ }^{1}$
}

VII International Congress of

${ }^{1}$ Escuela Superior Politécnica de Chimborazo, Riobamba, Ecuador

${ }^{2}$ Universidad Técnica Particular de Loja, Ecuador

Entrepreneurship and

Innovation (SECTEI 2020)

Corresponding Author:

E. Pozo

edison.pozo@espoch.edu.ec

Published: 26 August 2021

Production and Hosting by

Knowledge $\mathrm{E}$

(c) E. Pozo et al. This article is distributed under the terms of the Creative Commons

Attribution License, which permits unrestricted use and redistribution provided that the original author and source are credited.
S OPEN ACCESS

\section{Abstract}

The Decentralized Autonomous Municipal Government of the Francisco de Orellana canton is made up of the following rural parishes: Alejandro Labaka, Armenia, Dayuma, El Dorado, El Edén, García Moreno, Guayusa, Inés Arango, La Belleza, Nuevo Paraiso, Taracoa and the Urban Parish of El Coca. The Constitution of the Republic of Ecuador (2008) establishes the rights of nature and protects the biodiversity of the Amazon ecosystem. This is complemented by the provisions of the Organic Code of Territorial Organization, Autonomy and Decentralization (2010), the Organic Code of the Environment (2017) and also the Organic Law for the Integrated Planning of the Special Amazon Territorial District (2018). This article reviewed compliance with municipal agro-environmental legislation in the Decentralized Municipal Autonomous Government of the Francisco de Orellana canton. This analysis was based on the publication of the Organic Law for the Integrated Planning of the Special Territorial District of the Amazon in the Official Registry Supplement 245, dated May 21, 2018. A qualitative methodology was used. Data were collected through analysis of public policies, regulations, legislation and ordinances, and interviews with the main actors of the Decentralized Municipal Autonomous Government. The results suggested that the Municipal Government seeks to protect the biodiversity of the Amazon ecosystem by adopting sustainable development and conservation policies, but it is clear that ordinances are needed for agro-environmental education, garbage classification, recycling, organic gardens, and greater integration into municipal agro-environmental projects.

Keywords: agriculture, Amazon, environment, biodiversity, municipal, Ecuador.

\section{Resumen}

El Gobierno Autónomo Descentralizado Municipal del cantón Francisco de Orellana está integrado por las Parroquias Rurales:

Alejandro Labaka, Armenia, Dayuma, El Dorado, El Edén, García Moreno, Guayusa, Inés Arango, La Belleza, Nuevo Paraiso, Taracoa y la Parroquia Urbana de El Coca. La Constitución de la República del Ecuador (2008), establece los derechos de la naturaleza y protege la biodiversidad del ecosistema amazónico, esto se complementa con lo establecido en el Código Orgánico de Organización Territorial Autonomía y Descentralización (2010), el Código Orgánico del Ambiente (2017) y ademas la Ley Orgánica para la Planificación Integral de la Circunscripción Territorial Especial Amazónica (2018). Este artículo revisa el cumplimiento de la legislación agroambiental municipal en el Gobierno Autónomo Descentralizado Municipal 
del cantón Francisco de Orellana, este análisis se realiza a partir de la publicación de la Ley Orgánica para la Planificación Integral de la Circunscripción Territorial Especial Amazónica en el Registro Oficial Suplemento 245, de fecha 21 de mayo del 2018. La metodología utilizada se basó en un análisis cualitativo usando técnicas y herramientas como la obtención de datos, análisis de las políticas públicas, normativa, legislación, ordenanzas y entrevista con los principales actores del Gobierno Autónomo Descentralizado Municipal del cantón Francisco de Orellana. Los principales resultados sugieren que el Gobierno Municipal busque precautelar la biodiversidad del ecosistema amazónico, adoptando políticas de desarrollo sostenible y de conservación, pero es evidente que son necesarias ordenanzas encaminadas a la educación agroambiental, clasificación de la basura, reciclaje, huertos orgánicos, y una mayor integración en proyectos agroambientales municipales.

Palabras Clave: agricultura, Amazonía, ambiente, biodiversidad, municipal, Ecuador.

\section{Introducción}

El Ecuador se caracteriza por su riqueza en biodiversidad y tierras aptas para el cultivo, por lo que se busca garantizar un ambiente sano y ecológicamente equilibrado y la seguridad alimentaria de la población ya que las características de la tierra permiten cultivos, tropicales, de clima templado, fríos y amazónico, en sus cuatro regiones climáticas Litoral o Costa, Interandina o Sierra, Oriental o Amazónica e Insular o Galápagos, la legislación agroambiental municipal, es una temática que no se ha estudiado a profundidad en el Ecuador, y más aun en el cantón Francisco de Orellana, Provincia de Orellana que es el objeto de estudio de esta investigación, estudiar la legislación ambiental municipal de este cantón amazónico desde la entrada en vigencia de la Ley Orgánica para la Planificación Integral de la Circunscripción Territorial Especial Amazónica (2018).

Inicio refiriéndome primeramente al derecho ambiental donde se diferencia o distingue al 'derecho de protección de la naturaleza' (o de protección del ambiente natural) y el 'derecho ambiental de la tecnosfera' [1]. Partiendo de esta concepción tenemos claro que el derecho ambiental establece dos tipos de reglas que se complementan, estas son: una referente a la prevención y control de la contaminación ambiental y por otra parte la que se refiere a la conservación de recursos naturales [2].

Con el paso de los años y la evolución, perfeccionamiento y modernización del derecho ambiental se logró la unificación en la legislación ambiental de estos dos aspectos que se complementan.

Un nuevo concepto actualmente se refiere, a la legislación agroambiental, que consiste en la unificación del aspecto del agro es decir garantizar la seguridad alimentaria, con el aspecto ambiental, o el derecho a vivir en un medioambiente sano 
y ecológicamente equilibrado, la legislación agroambiental busca, pretende y tiene como objetivo garantizar a los agricultores un entorno medioambiental adecuado, que no afecte su producción o sus ganancias, en el caso de Europa por ejemplo en España el Reglamento 2078/92/CEE busca y tiene como objetivo fomentar prácticas agrarias que extensifiquen la producción, y promuevan la proteccion del medio ambiente y la conservación del medio natural, garantizando al mismo tiempo a los agricultores un nivel de renta adecuado, es decir obtener beneficios económicos y agroambientales [3], también en lo referente a la Agricultura de conservación que comprende una serie de técnicas que tiene como objetivo fundamental conservar, mejorar y hacer un uso más eficiente de los recursos naturales, mediante un manejo integrado del suelo, el agua, los agentes biológicos, y los 'inputs' externos, entendiéndose por estos a los insumos externos o combustible fósil que se puede emplear en forma racional y responsable [4].

Partiendo de los conceptos analizados, definimos a la legislación agroambiental ecuatoriana como el conjunto de instrumentos internacionales, tratados, convenios suscritos y ratificados por el Ecuador, y normativa, códigos, estatutos, leyes, reglamentos que tienen como objetivo la integración de las prácticas agrarias, agrícolas y medioambientales, para procurar un medio ambiente ecológicamente equilibrado y garantizar la seguridad alimentaria respetándolos derechos de la naturaleza, logrando por consiguiente el bienestar común de la población, y en el caso del Ecuador procurar el buen vivir y el equilibrio de los diferentes factores que interactúan en el ecosistema agroambiental ecuatoriano.

Refiriéndonos al Derecho Internacional del medio ambiente o el derecho internacional agroambiental, en el caso de nuestro país Ecuador, se ha realizado la suscripción y ratificación de varios instrumentos internacionales sobre medio ambiente y desarrollo sostenible, entre ellos tenemos los siguientes: La Convención de las Naciones Unidas para el Cambio Climático suscrita el 9 de junio de 1992 por el Ecuador, y ratificada en fecha 23 de febrero de 1993; Posteriormente el 15 de enero de 1999, se suscribió el Protocolo de Kyoto, ratificado en fecha 13 de enero de 2000; Se suscribió el 9 de junio de 1992 el Convenio de Diversidad Biológica, ratificado en fecha 23 de febrero de 1993; El 24 de mayo del 2000 se suscribió el Protocolo de Cartagena Sobre Seguridad de la Biotecnología, ratificado el 30 de enero del 2003; El 1 de abril del 2011, se suscribió el Protocolo de Nagoya sobre Acceso a los Recursos Genéticos y la Participación Justa y Equitativa en los Beneficios que se deriven de su utilización - ABS, ratificado por la Asamblea Nacional de la República del Ecuador el 15 de agosto del 2017; El 19 de enero de 1995, se suscribió la Convención de la Lucha contra la Desertificación y Sequia, ratificada por la Asamblea Nacional de la República del Ecuador el 6 de septiembre de 1995; La Convención Ramsar relativa a los Humedales ratificada por el Congreso Nacional del Ecuador el 7 de enero de 1991, El 13 de mayo de 1988 se 
suscribió la Convención sobre Comercio Internacional de Especies Amenazadas de Fauna y Flora Silvestres CITES, ratificada el 12 de julio de 1988.

El 1 de febrero del 2004 se ratificó la Convención sobre la Conservación de las Especies Migratorias de Animales Silvestres, CMS; El 18 de Febrero del 2003 se ratificó el Acuerdo de Albatros y Petreles (ACAP); El 20 de diciembre de 1979 se suscribió el Convenio para la conservación y manejo de la Vicuña, ratificado el 7 de mayo de 1982, El 31 de diciembre de 1998 se suscribió la Convención Interamericana para la protección y Conservación de las Tortugas Marinas - CIT, ratificado el 6 de octubre del 2000; El 23 de febrero de 1993 se ratificó el Convenio de Basilea sobre movimientos transfronterizos de los desechos peligrosos; El 7 de junio de 2004 se ratificó el Convenio de Estocolmo sobre Contaminantes Orgánicos Persistentes COPs; El 4 de mayo de 2004 se ratificó el Convenio de Rotterdam sobre procedimiento de consentimiento fundamentado previo sobre ciertos productos químicos peligrosos objeto del comercio internacional; El 11 de octubre de 2013 se suscribió el Convenio de Minamata sobre Mercurio, ratificado el 6 de abril del 2016; Referente a la Convención sobre Comercio

Internacional de Maderas Tropicales ITTO - OIMT, el Convenio Internacional de la OIMT de 2006 entró en vigor el 7 de diciembre de 2011 en reemplazo del convenio de 1994; Respecto a la caza de ballenas el instrumento internacional de la Comisión Ballenera Internacional (CBI) fue reactivado en marzo de 2008; En junio del 2001 se suscribió el Foro de Naciones Unidas sobre Bosques; y finalmente la Alianza para las Montañas donde el Ecuador fue adherido el 30 de mayo de 2006.

Refiriéndonos a los antecedentes históricos de la legislación agroambiental ecuatoriana, en lo que se refiere a normas agrarias debemos partir desde el año de 1875 en el que se expidieron varias leyes y normativa del agro, por lo que iniciamos por referirnos y mencionar a la Ley de Tierras Baldías que se expidió el 7 de diciembre de 1875, transcurridos más de cincuenta años el 13 de octubre de 1927 se expidió la Ley de Patrimonio Territorial; Mediante Decreto Legislativo Numero 1 de fecha 7 de abril de 1932 se promulgo en el Registro Oficial Numero 142 la Ley de Adjudicación de tierras de comunidad a indígenas [5]; después de cuatro años el 12 de mayo de 1936 se expidió la Ley de Tierras Baldías y Colonización [6].

De igual manera en esta misma década de los años 30, del siglo pasado surgen iniciativas por parte de los sectores sociales e indígenas, para realizar reformas en el aspecto agrario, ya que los terratenientes mantenían un sistema donde prestaban temporalmente sus tierras a los indígenas a cambio de trabajo, esta modalidad de explotación o nueva forma o modalidad de esclavitud se conocía como huasipungo [7].

La Iglesia Católica del Ecuador y el Partido Comunista del Ecuador, aunque ideológicamente antagónicos, y cada uno por su lado auspiciaron la reivindicación de los derechos de los movimiento sociales e indígenas, esto origino y permitió que en 1954 se realice el primer censo agropecuario, el que arrojo cifras alarmantes respecto a la mala 
distribución de la tierra, ya que existían grandes haciendas, propiedades e inmuebles rurales con grandes extensiones de tierra sin cultivar en manos de terratenientes, en contraste y contraposición con los niveles de pobreza extrema del sector campesino e indígena que no podían acceder al dominio y propiedad de la tierra e inmuebles rurales [8].

En 1960 durante la Presidencia Constitucional de la República del Ecuador del Dr. José María Velasco Ibarra, se conformó la Comisión Nacional de Reforma Agraria. Bajo este contexto histórico y el inicio de la siembra y cultivo de banano en la región Costa, donde se lo realizaba en propiedades de 50 hectáreas, origino el interés de la ciudadanía de todo el país para que se realice estas actividades agrícolas y se extiendan a nivel nacional con cultivos que se adecuen a cada región climática [9], todo esto permitió que mediante Decreto Supremo 1480 se expidiera la ley de Reforma Agraria y Colonización el 11 de julio de 1964 publicada mediante Registro Oficial Numero 297 de fecha 23 de julio de 1964 [10], y se creara el Instituto Ecuatoriano de Reforma Agraria y Colonización (IERAC), también mediante Decreto Supremo 3051 se expidió la ley de tierras Baldías y Colonización publicada en el Registro Oficial 342 de 28 de septiembre de 1964 [11].

Haciendo referencia al aspecto agroambiental, en la década de los setenta, del siglo pasado el Ecuador, recién inicio con la preocupación y la necesidad de implementar ciertas políticas ambientales referentes a evitar o mitigar la contaminación ambiental [9]. En esa misma década los pocos resultados que se obtuvieron de la aplicación de la Ley de Reforma Agraria y Colonización, motivaron que el 26 de febrero de 1970 se expidiera la ley reformatoria a la ley de Reforma Agraria y Colonización, y mediante Decreto Supremo 373 y publicación en el Registro Oficial número 54, de fecha 7 de septiembre de 1970 se promulgara la Ley de Abolición del trabajo precario en la Agricultura [12], en el Gobierno del Dr. José Maria Velasco Ibarra, también se expidió mediante Decreto Supremo Numero 918 de fecha 21 de junio de 1971, publicada mediante Registro Oficial Numero 253 de fecha 25 de junio de 1971 la Ley de Procedimiento Agrario [13]; Mediante Decreto Supremo Numero 962 de fecha 30 de junio de 1971 se promulgo en el Registro Oficial Numero 259 de fecha 5 de julio de 1971 la Ley de Fomento Agropecuario y Forestal [14].

En el aspecto agroambiental en 1971 se inició con la incorporar regulaciones ambientales el sector Hidrocarburífero con la publicación el 27 de septiembre de 1971 de la Ley de Hidrocarburos, posteriormente se expidió reglamentos y legislación o normativa conexa, obligando a seguir ciertos protocolos o procedimientos en la actividad hidrocarburífera; En el aspecto del agro mediante Decreto Supremo 196, promulgada en el Registro Oficial Numero 2 de fecha 17 de febrero de 1972 se expidió la Ley Especial para Adjudicación de Tierras Baldías en la Amazonía [15]. La Ley de Hidrocarburos fue codificada en el año 1978 mediante Decreto Supremo Numero 2967 publicada 
en el Registro Oficial Numero 711 de fecha 15 de noviembre de 1978 [16], desde esa época en dicha Ley se establecieron obligaciones ambientales para quienes realizaban actividades Hidrocarburíferas [9]. En lo referente al agro en 1973 el General Guillermo Rodríguez Lara durante su administración expide una nueva ley de Reforma Agraria, clara, beneficiosa, ambiciosa y radical ya que condicionaba que se explote eficientemente más del $80 \%$ del predio para no ser sujeto de afectación, y adjudicación a terceros [8]. La legislación ambiental logra un gran avance y debemos tomar como punto de partida de la legislación especializada ambiental el año de 1976, ya que en este año se da la expedición mediante Decreto Supremo No. 374, publicado en el Registro Oficial No. 97 de 31 de mayo de 1976 de la Ley de Prevención y Control de la Contaminación Ambiental, donde ya se le da un trato especializado e independiente de otras legislaciones a la legislación ambiental [17], ademas se incorporaron por primera vez mecanismos de proteccion como la acción popular para denunciar y poner en conocimiento de autoridades administrativas y judiciales casos de contaminación ambiental en lo referente al aire, agua y suelo aunque en forma general, estableciendo también, el procedimiento administrativo sancionador de ese tipo de infracciones [9], después de dos años en 1978 se codifico la Ley de Hidrocarburos en el que el aspecto ambiental tiene un mayor trascendencia, relevancia e importancia estableciéndose la obligación y responsabilidad del Estado para controlar que la actividad del sector de hidrocarburos no afecte el medio ambiente estableciendo las auditorías ambientales como un mecanismo y herramienta de control y vigilancia [9].

En contradicción y para más bien frenar los avances de la reforma agraria, se expidió Mediante Decreto Supremo 3289, publicado en el Registro Oficial 792 de fecha 15 de marzo de 1979, la Ley de Fomento y Desarrollo Agropecuario [18], se direccionó y busco únicamente frenar los avances de la reforma agraria y más bien garantizó la propiedad privada de la tierra de los grupos dominantes, que acumulaban grandes extensiones de tierras ociosas, que no se cultivaban acumulando los bienes e inmuebles rurales en grupos hegemónicos y dominantes, que acaparaban y querían seguir acumulando grandes extensiones de tierra, mientras que los grupos sociales y sector indígena carecían de propiedades e inmuebles rurales [18].

Este tipo de contradicciones origino el fracaso de la reforma agraria por lo que en las décadas del 80 y 90 del siglo pasado se presentaron varios proyectos de Ley para su debate y aprobación en la función legislativa de ese entonces el Congreso Nacional de la República del Ecuador, entre los proyectos que se presentaron en la función legislativa tenemos a los siguientes: Proyecto de Código Agrario, que se presentó durante la presidencia del Dr. Oswaldo Hurtado Larrea (1981-1984), Proyecto de Ley Agraria Integral, propuesto por la CONAIE en el año de 1993 durante el gobierno del Arq. Sixto Durán Ballen (1992-1996), igualmente durante esta administración se presentaron varios proyectos, por ejemplo en el año 1993 se presentó el proyecto de 
Ley Agraria presentado por la Cámara de Agricultura de la Primera Zona, y el Proyecto de Ley de Reforma Agraria presentado por el Instituto Ecuatoriano de Reforma Agraria y Colonización (IERAC), en cambio en el año 1994 se presentó el Proyecto de Ley de Ordenamiento del Sector Agrario propuesta por el Arq. Sixto Durán Ballén[8].

En el aspecto Constitucional y supremacía constitucional, la Constitución de la República del Ecuador publicada en el Registro Oficial el 27 de marzo de 1979 que estuvo vigente desde el 10 de agosto de ese año, incorporo por primera vez la materia ambiental con rango constitucional. Esto influyo y originó que para adaptarse al nuevo marco y contexto constitucional se realizaran reformas en el año 1982 en La Ley de Hidrocarburos, dichas reformas e innovaciones se dieron en lo referente al manejo ambiental, especialmente en lo referente a que en los contratos en materia hidrocarburífera y lo relacionado con el sector de hidrocarburos se incluyan y consten clausulas con garantías relacionadas con la normativa y practica internacional en materia de preservación de la industria agropecuaria y riqueza ictiológica [9] esto con el fin de procurar la seguridad alimentaria y proteger el sector agropecuario, y lo referente a acuacultura, piscicultura y pesca, donde se debe evitar la contaminación del agua de cualquier fuente natural, lagos, lagunas, ríos o mares por reunir una gran biodiversidad ictiológica.

En 1983 Mediante Registro Oficial No. 569 de fecha 1 de septiembre de 1983 se publicó la reforma a la Constitución de la República del Ecuador publicada en el Registro Oficial el 27 de marzo del año 1979 [19] donde en el capítulo referente al derecho de propiedad se incorporó y estableció el derecho de todos los ecuatorianos a vivir en un ambiente sano, por consiguiente, dándose la pauta para que se expidan normativas en busca de un medioambiente sano y ecológicamente equilibrado en nuestro país [9]. En el ámbito y aspecto del agro y la agricultura ante la presión social de los grupos sociales, indígenas y la población rural del país el Dr. Rodrigo Borja Cevallos (1988-1992) durante su periodo presidencial constitucional en 1990 adjudico títulos de dominio y propiedad de predios rústicos o rurales, que comprendían alrededor de dos millones de hectáreas [7].

Retomando lo referente a el área de Hidrocarburos y legislación hidrocarburífera y legislación ambiental en el año 1993 se expidió el Reglamento de Operaciones Hidrocarburíferas $(\mathrm{ROH})$ para regular lo referente a obligaciones y normas ambientales [9]. En el aspecto de la legislación agraria, agrícola, agropecuaria mediante Registro Oficial número 461 de fecha 14 de junio de 1994 se publicó la Ley de Desarrollo Agrario [20], pero por asuntos políticos, sociales y complementar con ciertos criterios que no habrían sido considerados en su expedición y posterior publicación, fue reformada prácticamente en su totalidad, el mismo año de su publicación, dicha reforma se publicó mediante Registro Oficial número 504 de fecha 15 de agosto de 1994 [21]. 
En el año de 1995 nuevamente se realizaron reformas en la legislación ambiental e hidrocarburífera, remplazándose el Reglamento de Operaciones Hidrocarburíferas $(\mathrm{ROH})$, por el Reglamento Ambiental de Operaciones Hidrocarburíferas ( $\mathrm{ROH}$ ) que derogó el anterior e incorporo varias innovaciones y reformas en lo referente a calidad ambiental, procedimientos de autorización y límites permisibles de emisiones, descargas y vertidos [9].

En la Constitución Política de la República del Ecuador de 1998 publicada mediante Registro Oficial Numero 1 de fecha 11 de agosto de 1998 [22]. En lo referente al aspecto agroambiental se incorporó y estableció la obligación por parte del Estado de garantizar la preservación de la naturaleza para ello debe seguirse lo estipulado en leyes y reglamentos del sector agroambiental, también en la Sección denominada Medio Ambiente se incorporaron y agregaron a partir del articulo 44 disposiciones que establecían el derecho a vivir en un medio ambiente sano para toda la población, estableciendo y estipulando que se garantice el desarrollo sustentable, agregándose e incorporándose por primera vez principios como el de prevención, precaución y otros aspectos fundamentales para permitir a la sociedad ecuatoriana vivir en un medioambiente sano y ecológicamente equilibrado [22]. Posteriormente se publicó en el Registro Oficial número 245, de fecha 30 de julio de 1999 la Ley de Gestión Ambiental

[23] en la que el Estado pasa a ser el protagonista y garante de la protección ambiental, y se crea el Sistema Nacional Descentralizado de Gestión Ambiental como un mecanismo e institución de coordinación transectorial, de interacción y de cooperación entre los distintos ámbitos, sistemas y subsistemas de manejo y gestión ambiental, Esta legislación estableció el sistema de evaluación de impacto ambiental previo al otorgamiento de la licencia o permiso ambiental obligatorio que deben tener los diferentes proponentes de actividades $u$ obras que puedan representar un riesgo ambiental [9].

También se instauró e implemento mecanismos de participación ciudadana en la gestión ambiental para lograr una participación más activa de la ciudadanía cuando tengan conocimiento o evidencien vulneración de un hábitat o ecosistema [9]. Finalmente, la Ley estableció reglas procesales y sustantivas claras para la presentación de demandas o denuncias en pro de la protección de los derechos ambientales. En el aspecto Hidrocarburífero se reforma la Ley de Hidrocarburos en el año 2000 , en el sentido de incorporar en la ley disposiciones de carácter reglamentario que constaban desde 1995 en el Reglamento Ambiental de Operaciones Hidrocarburíferas $(\mathrm{ROH})$ en lo referente a realizar estudios de impacto ambiental y planes de manejo ambiental para prevenir, mitigar, rehabilitar y compensar los impactos ambientales y sociales derivados de las actividades Hidrocarburíferas, estos estudios de impacto ambiental serán evaluados directamente o por delegación a firmas auditoras que estén 
calificadas para dicha actividad. En el año 2001 mediante Decreto Ejecutivo número 1215 publicado en el Registro Oficial Numero 265 de fecha 13 de febrero del 2001 se publica el Reglamento Ambiental de Actividades Hidrocarburíferas (RAOH) [24], que reemplazo al antiguo Reglamento Ambiental de Operaciones Hidrocarburíferas, el cual estableció en el Ecuador un sistema de manejo, gestión y control ambiental de la actividad hidrocarburífera para procurar un medio ambiente sano.

Respecto al ámbito normativo agroambiental, en el año 2003 el Ecuador dictó una compilación de los Reglamentos dictados en materia ambiental, en el Texto Unificado de Legislación Ambiental Secundaria (TULAS o TULSMA), el cual tiene once libros [24]. En los aspectos fundamentales de Biodiversidad, la Ley Forestal y de Conservación de Áreas Naturales y Vida Silvestre [25]. Publicada en el Registro Oficial Suplemento No. 418 de 10 de septiembre de 2004, regulaba los aspectos concernientes al patrimonio forestal del Estado, Conservación de Áreas Naturales y Vida Silvestre [25]. El 23 de julio del 2008 en el Centro Cívico 'Ciudad Alfaro', cantón Montecristi, provincia de Manabí, se suscribió el Mandato Constituyente Numero 16, que estableció como política de Estado el diseñar y ejecutar en forma emergente un Programa de Soberanía Alimentaria, con vigencia hasta el 31 de diciembre del 2009, cuyo objetivo será incrementar la productividad, fomentar el crecimiento del sector agropecuario en el país y el ejercicio de actividades agropecuarias sustentables y responsables con la naturaleza y el ambiente [26], con este mandato en el aspecto de la legislación agroambiental se buscó la soberanía alimentaria, mejorar la producción y productividad, apoyar al sector agropecuario en su crecimiento y desarrollo, y algo fundamental y trascendental en el aspecto agroambiental que es promover actividades agropecuarias sustentables y responsables con la naturaleza y el medioambiente.

La Constitución de la República del Ecuador del año 2008 publicada mediante Registro Oficial Numero 449 de fecha 20 de octubre del 2008, incorporo por primera vez y es un referente constitucional a nivel mundial en lo que se refiere a derechos de la naturaleza, ya que incorporo a partir del articulo 71 la proteccion constitucional de la naturaleza y sus derechos [27], e introdujo normas relativas a responsabilidad ambiental como por ejemplo la imprescriptibilidad de la acción por daño ambiental que quiere decir que se puede proteger a la naturaleza a pesar de que transcurra cierto periodo de tiempo desde la vulneración de sus derechos, por consiguiente se puede denunciar e investigar en cualquier tiempo, la responsabilidad objetiva que quiere decir que tanto personas naturales como jurídicas serán responsables y deberán ser sancionadas y ademas reparar el daño causado a la naturaleza, la carga de la prueba del demandado respecto a la inexistencia de daño potencial o real que quiere decir que el demandado o denunciado está en la obligación de presentar las pruebas de descargo, mientras que lo que alegue la parte que denuncia la vulneración de derechos de la naturaleza se lo tendrá como cierto hasta que sea contradicho con fundamento 
de hecho y de derecho por la parte demandada, y finalmente el indubio pro natura que quiere decir que siempre y en todos los casos se resolverá lo más favorable y lo que más convenga con el fin de garantizar los derechos de la naturaleza. Por cuanto este trabajo investigativo se centra en el análisis de la Legislación Agroambiental municipal debemos mencionar lo que estable la Constitución de la República del Ecuador (2008), en el artículo 242 en lo que se refiere a la Organización territorial del País, se señala lo siguiente: [...]

El Estado se organiza territorialmente en regiones, provincias, cantones y parroquias rurales. Por razones de conservación ambiental, étnico- culturales o de población podrán constituirse regímenes especiales. Los distritos metropolitanos autónomos, la provincia de Galápagos y las circunscripciones territoriales indígenas y pluriculturales serán regímenes especiales. [..,27].

Es decir claramente se establece que una de las divisiones político administrativas y territoriales del País son los cantones o Gobierno Autónomos Descentralizados Municipales o Metropolitanos, en el caso de la presente investigación el objeto de estudio fue el Gobierno Autónomo Descentralizado Municipal de Francisco de Orellana en la Provincia de Orellana y la verificación del cumplimiento de la legislación agroambiental [28]. Es importante destacar la biodiversidad de la amazonia ecuatoriana, donde se ubica el mayor parque nacional del País, el Parque Nacional Yasuní el que esta ubicado en las Provincias de Orellana y Pastaza, una de las áreas y zonas más biodiversas del planeta y un ecosistema único hábitat de muchas especies de flora y fauna [28], y por ello es fundamental lo que establece la Constitución de la República del Ecuador 2008, especialmente en su artículo 250, donde señala lo siguiente: El territorio de las provincias amazónicas forma parte de un ecosistema necesario para el equilibrio ambiental del planeta.

Este territorio constituirá una circunscripción territorial especial para la que existirá una planificación integral recogida en una ley que incluirá aspectos sociales, económicos, ambientales y culturales, con un ordenamiento territorial que garantice la conservación y protección de sus ecosistemas y el principio del sumak kawsay [27]. Ademas respecto a la amazonia y legislación agroambiental la Constitución de la República del Ecuador 2008 en el artículo 259, ha establecido lo siguiente: Con la finalidad de precautelar la biodiversidad del ecosistema amazónico, el Estado central y los gobiernos autónomos descentralizados adoptarán políticas de desarrollo sustentable que, adicionalmente, compensen las inequidades de su desarrollo y consoliden la soberanía [27] es decir los Gobiernos Autónomos Descentralizados están en la obligación de implementar y adoptar políticas de desarrollo sustentable, que busquen compensar las inequidades que puedan existir, y el en el objeto de estudio estas inequidades se buscaría eliminar en los Gobiernos Autónomos Descentralizados Municipales de la Amazonía ecuatoriana. 
En lo que respecta a la ley de Minería Aprobada el 26 de enero de 2009 y publicada en el Registro Oficial No. 517 de jueves 29 de enero de 2009 [29], se encarga de regular las relaciones del Estado con las personas naturales y jurídicas, nacionales o extranjeros y las de estas entre sí, respecto de la obtención de derechos y ejecución de actividades mineras en el territorio ecuatoriano, además recoge el principio de propiedad estatal de los recursos minerales o nacionalización de los recursos naturales no renovables [9].

Ademas contiene todas las normas que regulan la actividad minera en el Ecuador, su contenido abarca las competencias, instituciones, áreas, fases, derechos y concesiones mineras; modalidad contractual, directrices para el desarrollo sustentable de las actividades en armonía con el medio ambiente y las características de los regímenes de la minería (minería artesanal, pequeña minería, etc.) [9].

El Reglamento Ambiental de Actividades Mineras Expedido mediante Decreto Ejecutivo No. 121 de 04 de noviembre de 2009, publicado en el Registro Oficial No. 67 de 16 de noviembre de 2009 [30], establece la normativa técnica ambiental que regula dentro del territorio nacional la gestión ambiental en las actividades mineras en sus fases iniciales de exploración, explotación inicial y avanzada, y posteriormente también regula las fases de explotación, beneficio, comercialización y cierre de minas concesionadas por el Estado ecuatoriano [9].

Esto es fundamental ya que tiene como objetivo que en todo el proceso de extracción minera se respete la normativa técnica ambiental, no se quedara ninguna fase o etapa de explotación minera sin seguir y cumplir protocolos y pasar filtros establecidos por la legislación agroambiental ecuatoriana.

El Código Orgánico de Organización Territorial Autonomía y Descentralización (COOTAD), publicado en el Registro Oficial Suplemento

303 de fecha 19 de octubre de 2010 [31], respecto a la Legislación agroambiental municipal y la amazonia, en su artículo 11 establece lo siguiente: [...] Ecosistema amazónico. El territorio de las provincias amazónicas forma parte de un ecosistema necesario para el equilibrio ambiental del planeta.

Este territorio constituirá una circunscripción territorial especial regida por una ley especial conforme con una planificación integral participativa que incluirá aspectos sociales, educativos, económicos, ambientales y culturales, con un ordenamiento territorial que garantice la conservación y protección de sus ecosistemas y el principio del sumak kawsay.

En la propuesta de la ley especial amazónica deberán participar personas, comunidades, pueblos, nacionalidades y colectivos urbanos y rurales. Se respetará la integralidad de los territorios de las comunidades, pueblos y nacionalidades amazónicas, los derechos colectivos y los instrumentos internacionales [...,31]. Por lo que el Código 
Orgánico de Organización Territorial Autonomía y Descentralización, para complementar lo establecido en la Constitución de la República del Ecuador busca también la participación ciudadana, de todas las personas, comunidades, pueblos, nacionalidades y colectivos urbanos y rurales y por consiguiente la participación fundamental de los Gobiernos Autónomos Descentralizados Municipales Cantonales amazónicos, y también se refiere al ordenamiento territorial donde los Gobiernos Autónomos Descentralizados Municipales tienen un papel muy importante en el aspecto agroambiental [28]. Refiriéndonos nuevamente al aspecto minero, el Reglamento Ambiental de Actividades Mineras fue reformado mediante Acuerdo Ministerial No. 37 publicado en el Registro Oficial Suplemento No. 213 de 27 de marzo de 2014 [32]. Respecto al aspecto agroambiental de la Provincia de Galápagos, este se rige por lo dispuesto en la Ley Orgánica de Régimen Especial de la Provincia de Galápagos Publicada en el Registro Oficial Suplemento No. 520 de 11 de junio de 2015 [33], y se complementa con lo establecido en el Reglamento a la Ley de Régimen Especial de la Provincia de Galápagos Publicado en el Registro Oficial Suplemento No. 989 de 21 de abril de 2017 [34], estos cuerpos legales establecen el régimen jurídico administrativo aplicable en el archipiélago, regulando las actividades a realizarse en la provincia de Galápagos en el marco de los limites agroambientales y tomando en cuenta la biodiversidad y las condiciones propias y únicas de esta provincia [9]. Durante, mucho tiempo estuvo regulado en el TULAS dentro del Libro VII dentro del título I, el Régimen Especial de Galápagos, sin embargo en el año 2015, este título fue derogado por la Ordenanza Provincial No. 001- CGREG-2015 [35], publicada en el Registro Oficial Suplemento No. 550 de 5 de abril de 2016, donde se establece el Plan para el Desarrollo Sustentable y Ordenamiento de la Provincia de Galápagos que actualmente rige para regular las actividades en todas las islas del archipielago.

Mediante Registro Oficial Suplemento 711 de fecha 14 de marzo del 2016, se publicó la Ley Orgánica de Tierras Rurales y Territorios Ancestrales [36], esta ley busca normar el uso y acceso a la propiedad de la tierra rural o bines inmuebles rurales que carecen de título de dominio y cuyo titular de dominio es el Estado ecuatoriano, regula también el derecho a la propiedad de la misma que deberá cumplir la función social y la función agroambiental. Algo sumamente fundamental es que esta ley regula la posesión, la propiedad, la administración y redistribución de la tierra rural como factor de producción para garantizar la soberanía alimentaria, mejorar la productividad, propiciar un ambiente sustentable y equilibrado, y otorgar seguridad jurídica a los titulares de derechos de posesión de tierras rurales y territorios ancestrales [37].

En el Registro Oficial número 983 de 12 de abril del 2017, se publicó el Código Orgánico del Ambiente [38], pero al aplicarse la vacatio legis en este cuerpo legal se esperó un año desde su publicación para entrar en plena vigencia, hecho que se dio 
el 13 de abril del 2018, fecha desde la cual está vigente. Este Código Orgánico especializado en materia ambiental, ya no regula exclusivamente el régimen institucional, el sistema de calidad y gestión ambiental y la responsabilidad ambiental, sino que abarca otros temas trascendentales como el tratamiento de la biodiversidad, del régimen marino costero, del cambio climático y el régimen sancionatorio [9, 38]. El Código Orgánico del Ambiente se encuentra dividido en siete libros y un libro preliminar de los cuales el libro primero tiene gran relación con el objeto de estudio de esta investigación ya que se refiere al Régimen Institucional donde establece como principales facultades de los Gobiernos Autónomos Descentralizados Metropolitanos y Municipales en materia agroambiental las siguientes: Regular y controlar el manejo responsable de la fauna y arbolado urbano, controlar el cumplimiento de los parámetros ambientales y la aplicación de normas técnicas de los componentes agua, suelo, aire y ruido, controlar las autorizaciones administrativas otorgadas, insertar criterios de cambio climático en los planes de desarrollo y ordenamiento territorial y demás instrumentos de planificación cantonal de manera articulada con la planificación provincial y las políticas nacionales, entre otras [9, 38]. Ademas se establecen facultades de los Gobiernos Autónomos Descentralizados Parroquiales Rurales en el Código Orgánico del Ambiente, dichas facultades son las siguientes: Insertar criterios de cambio climático en los Planes de Desarrollo y Ordenamiento Territorial y demás instrumentos de planificación parroquial de manera articulada con la planificación provincial, municipal y las políticas nacionales, promover la educación ambiental, organización y vigilancia ciudadana de los derechos ambientales y de la naturaleza, entre otras, pero es fundamental la articulación con los gobiernos autónomos descentralizados municipales [9, 38].

Con el constante crecimiento de la población en los municipios, sobre todo el crecimiento de la población urbana, se plantean problemas agroambientales que deben solucionarse a corto plazo, para garantizar el desarrollo sustentable y sostenible de la población. El objetivo de este trabajo fue analizar la legislación agroambiental municipal y nos hemos propuesto estudiar como estudio de caso el cantón Francisco de Orellana (Provincia de Orellana, Ecuador) desde la entrada en vigencia de la Ley Orgánica para la Planificación Integral de la Circunscripción Territorial Especial Amazónica publicado en el Registro Oficial Suplemento 245 de fecha 21 de mayo de 2018 [39]. ya que esta ley además de aportar al Derecho Administrativo y a la Regionalización, también aporta mucho a la Legislación Agroambiental y Legislación Agroambiental Municipal. Adentrándonos un poco más en las características de la región amazónica su territorio y el objeto de investigación que es el Gobierno Autónomo Descentralizado Municipal del cantón Francisco de Orellana, mencionamos que este municipio se caracteriza por sus ingresos económicos provenientes de las actividades Hidrocarburíferas, y porque su capital la Parroquia urbana y ciudad de El Coca es un centro económico y de prestación de insumos y servicios para toda la población de la cuenca de los ríos 
Coca, Napo y Payamino, ademas se caracteriza por recibir ciudadanos de todas las partes del país e inclusive de los vecinos países de Perú y Colombia, lo que ademas de su biodiversidad única, la convierte en una sociedad muy diversa en su aspecto social y cultural, esto conlleva también grandes retos en el aspecto agroambiental, ya que existen tierras fértiles aptas $p$ el cultivo pero también se debe respetar zonas y áreas que están protegidas y donde se desarrollan y es el hábitat de muchas especies animales, vegetales y varias nacionalidades indígenas de nuestro país.

\section{Metodología}

Para analizar el cumplimiento de la legislación agroambiental municipal desde la entrada en vigencia de la Ley Orgánica para la Planificación Integral de la Circunscripción Territorial Especial Amazónica se realizó un análisis y levantamiento bibliográfico con los documentos disponibles en internet en páginas oficiales [40], e información suministrada por el Gobierno Autónomo Descentralizado Municipal del Cantón Francisco de Orellana. En base a la documentación recopilada se realizó un análisis crítico de la información (Tabla 1) [41].

\section{1. Área de estudio}

El Gobierno Autónomo Descentralizado Municipal del Cantón Francisco de Orellana se encuentra ubicado al noreste de la Circunscripción Territorial Especial Amazónica (CTEA) y forma parte de la Zona de Planificación 2 aunque todavía no logra articularse legalmente, estaría conformada tentativamente por las provincias de Pichincha, Napo y Orellana, provincia a la cual pertenece (Figura 1) [41]. El área o superficie cantonal ocupa un total de $7,047 \mathrm{~km}^{2}$ (704.755 ha), en un rango altitudinal que va desde los 100 a los 720 m.s.n.m. Si nos referimos a la distancia con relación al Distrito Metropolitano de Quito, capital de la República del Ecuador, la cabecera cantonal la Parroquia Urbana y ciudad de El Coca se encuentra a una distancia aproximada de $300 \mathrm{~km}$ [41].

Al referirnos a los limites el cantón limita al Norte con el cantón La Joya de los Sachas (Provincia de Orellana) y los cantones Cascales y Shushufindi (Provincia de Sucumbíos); al Sur con los cantones Arajuno (Provincia de Pastaza) y Tena (Provincia de Napo), al Este con el cantón Aguarico (Provincia de Orellana) y al Oeste con el cantón Loreto (Provincia de Orellana) y Tena (Provincia de Napo) (Figura 2) [41].

Respecto a antecedentes históricos y división político administrativa del cantón Francisco de Orellana manifestamos que Francisco de Orellana, fue creado como cantón de la provincia de Napo mediante Decreto Legislativo publicado en el registro oficial Nro. 169 del 30 de abril de 1969 [41]. 


\section{Table 1}

Recursos bibliográficos consultados para el análisis de la legis/ación agroambiental municipal del Gobierno Autónomo Descentralizado Municipal de Francisco de Orellana, desde la entrada en vigencia de la Ley Orgánica para la Planificación Integral de la Circunscripción Territorial Especial Amazónica [40].

\section{Tema}

Instrumentos

Internacionales sobre

Medioambiente y desarrollo sostenible suscritos y ratificados por el Ecuador.

Normativa

Constitucional

Políticas Públicas agroambientales Códigos y Leyes Agroambientales Nacionalesy Legislación Regional y de Descentralización Legislación de Circunscripciones Territoriales Especiales Legislación Ambiental municipal (Ordenanzas)

\section{Fuente}

- Convención de las Naciones Unidas para el Cambio Climático suscrita el 9 de junio de 1992, ratificada en fecha 23 de febrero de 1993.

-Protocolo de Kyoto suscrito el 15 de enero de 1999, ratificado en fecha 13 de enero de 2000.

- Convenio de Diversidad Biológica suscrito el 9 de junio de 1992, ratificado en fecha 23 de febrero de 1993.

- Protocolo de Cartagena Sobre Seguridad de la Biotecnología suscrito el 24 de mayo del 2000, ratificado el 30 de enero del 2003.

-Protocolo de Nagoya sobre Acceso a los Recursos Genéticos y la

Participación Justa y Equitativa en los Beneficios que se deriven de su utilización - ABS, ratificado por la Asamblea

Nacional de la República del Ecuador el 15 de agosto del 2017.

- Convención de la Lucha contra la Desertificación y Sequia suscrito el 19 de enero de 1995, ratificado el 6 de septiembre de 1995.

- Convención Ramsar relativa a los Humedales ratificada el 7 de enero de 1991 , Convención sobre Comercio Internacional de Especies Amenazadas de Fauna y Flora Silvestres CITES suscrita el 13 de mayo de 1988, ratificada el 12 de julio de 1988.

-Convención sobre la Conservación de las Especies Migratorias de Animales Silvestres, CMS, ratificada el 1 de febrero del 2004.

-Acuerdo de Albatros y Petreles (ACAP), ratificada el 18 de Febrero del 2003 - Convenio para la conservación y manejo de la Vicuña suscrito el 20 de diciembre de 1979, ratificado el 7 de mayo de 1982.

-Convención Interamericana para la protección y Conservación de las Tortugas Marinas - CIT suscrito el 31 de diciembre de 1998, ratificado el 6 de octubre del 2000.

- Convenio de Basilea sobre movimientos transfronterizos de los desechos peligrosos, ratificado el 23 de febrero de 1993

- Convenio de Estocolmo sobre Contaminantes Orgánicos Persistentes COPs, ratificado el 7 de junio de 2004; Convenio de Rotterdam sobre procedimiento de consentimiento fundamentado previo sobre ciertos productos químicos peligrosos objeto del comercio internacional, ratificado el 4 de mayo de 2004 . - Convenio de Minamata sobre Mercurio, suscrito el 11 de octubre de 2013 ratificado el 6 de abril del 2016.

- Convención sobre Comercio Internacional de Maderas Tropicales ITTO OIMT, el Convenio Internacional de la OIMT de 2006 entró en vigor el 7 de diciembre de 2011 en reemplazo del convenio de 1994.

- Comisión Ballenera Internacional (CBI) reactivado en marzo de 2008

- Foro de Naciones Unidas sobre Bosques suscrito en junio del 2001. -Alianza para las Montañas donde se adherido el 30 de mayo de 2006. - Constitución de la Republica del Ecuador, 2008.

-Plan Nacional de Desarrollo Toda un Vida (2017- 2021).

- Ley de Fomento y Desarrollo Agropecuario, 1979.

- Ley de Tierras Rurales y Territorios Ancestrales 2016.

- Código Orgánico del Ambiente, 2017.

-Código Orgánico de Organización Territorial Autonomía y Descentralización, 2010.

- Ley Orgánica para la Planificación Integral de la Circunscripción Territorial Especial Amazónica, 2018.

- Ordenanzas del Gobierno Autónomo Descentralizado Municipal de Francisco de Orellana, 2018, 2019 y 2020. 


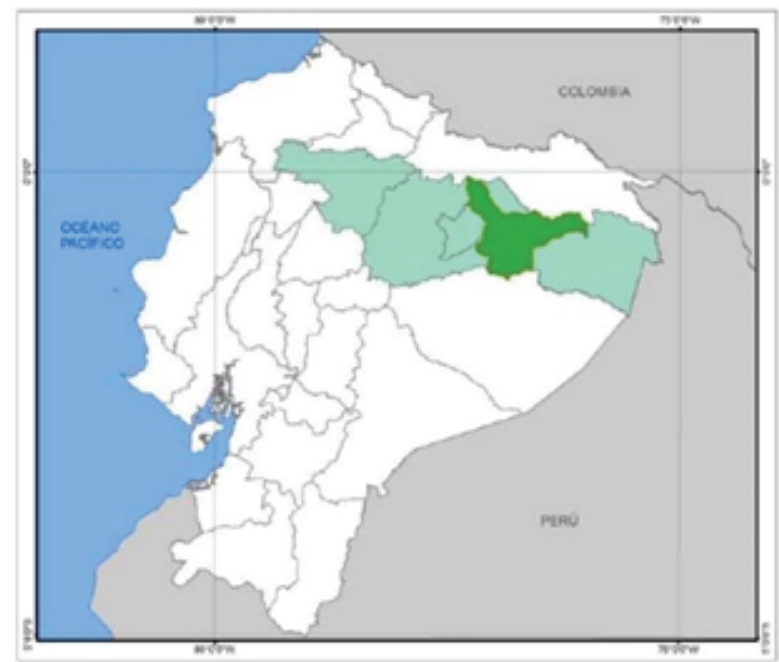

Figure 1

Mapa de ubicación geográfica de Francisco de Orellana (Orellana, Ecuador) (PDyOT GADMFO 2014-2019) [41].

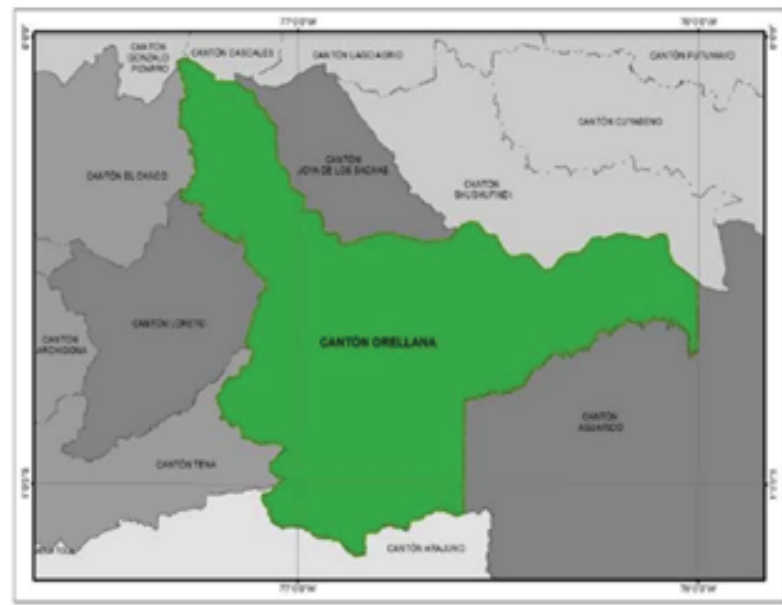

Figure 2

Mapa del cantón Francisco de Orellana (Orellana, Ecuador) (PDyOT GADMFO 2014-2019) [41].

Las primeras parroquias que conformaron el cantón fueron Puerto Francisco de Orellana (actualmente denominada EI Coca), Taracoa y Dayuma [41]. Con la provincialización de Orellana en el año de 1999, se crearon las parroquias de San José de Guayusa, Nuevo Paraíso, San Luis de Armenia, García Moreno, La Belleza, Alejandro Labaka, Inés Arango, El Dorado y El Edén (Figura 3).

Según datos del VII Censo de Población y VI de Vivienda, la población del cantón Francisco de Orellana asciende a 72.795 habitantes con una densidad poblacional de 10 hab/km² (**INEC, 2010). El 55,95\% de la población del cantón habita en el área urbana de El Coca, mientras el restante $44,05 \%$ se localiza de forma dispersa en las zonas rurales [41]. 


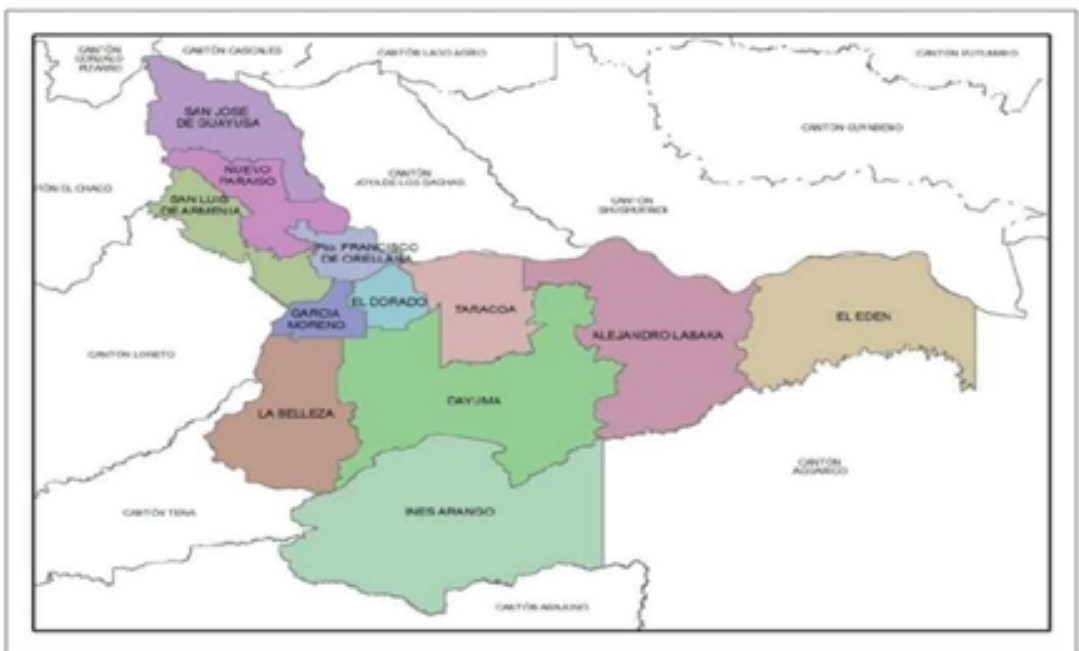

Figure 3

Mapa de la división político-administrativa del cantón Francisco de Orellana (Orellana, Ecuador) (PDyOT GADMFO 2014-2019) [41].

\section{Desarrollo y Discusión}

La Ley Orgánica para la Planificación Integral de la Circunscripción territorial especial Amazónica, aprobada por la Asamblea Nacional del Ecuador, publicado en el Registro Oficial Suplemento 245 de fecha 21 de mayo de 2018 [39], establece en su artículo 1 lo siguiente: [...] La presente ley tiene por objeto regular la Planificación Integral de la Circunscripción Territorial Especial Amazónica y su ordenamiento territorial observando aspectos sociales, económicos, culturales y ambientales' [...,39].

Este artículo analiza La Ley Orgánica para la Planificación Integral de la Circunscripción territorial especial Amazónica, desde su aporte en la legislación agroambiental, y que cosas se pueden mejorar y reformar para que se logre plasmar en la práctica la equidad en la Circunscripción Territorial Especial Amazónica y el cumplimiento de la legislación agroambiental [38].

Es fundamental el cumplimiento de la legislación agroambiental municipal en el territorio del Gobierno Autónomo Descentralizado Municipal del cantón Francisco de Orellana, ya que el territorio de la Circunscripción Territorial Especial Amazónica (CTEA), tiene una importancia a nivel mundial, ya que es fundamental y necesaria su riqueza en biodiversidad, flora, fauna y fuentes de agua dulce para mantener el equilibrio ambiental del planeta [38]. La Constitución ha establecido la importancia de que se cree la Circunscripción Territorial Especial Amazónica donde exista y conste una planificación integral de todos los actores y Gobiernos Autónomos Descentralizados Provinciales, Cantonales o Municipales y Parroquiales Rurales, mediante la Ley Orgánica para la Planificación Integral de la Circunscripción Territorial Especial Amazónica [38]. 
El gobierno actual, del presidente Lenin Boltaire Moreno Garcés, en el Plan Nacional de Desarrollo Toda un Vida (2017-2021), se ha planteado en el objetivo 3: 'Garantizar los derechos de la naturaleza para las actuales y futuras generaciones' y el Objetivo 6 dice: Desarrollar las capacidades productivas y del entorno para lograr la soberanía alimentaria y el Buen vivir rural, relacionado con el sector agrícola [42].

Es decir se reconoce la importancia de del aspecto agroambiental especialmente los derechos de la naturaleza y la obligación de mantenerla y conservarla para las presentes y futuras generaciones, ademas se busca el buen vivir del sector rural que siempre ha carecido de servicios y se ha mantenido con muchas necesidades, se busca su mejoramiento con el desarrollo de la producción del agro respetando los derechos de la naturaleza para lograr la soberanía alimentaria.

En el Plan Nacional de Desarrollo (PND), se propone alcanzar 18 de las metas en el sector agrícola al 2021; entre las principales metas tenemos: Reducir la incidencia de la pobreza por ingreso rural del 38,2\% al 31,9\% al 2021; Incrementar la tasa de empleo adecuado en el área rural del $27 \%$ al $35,2 \%$ al 2021; Reducir del 59,9\% al 49,2\% la tasa de pobreza multidimensional en el área rural al 2021; Reducir la concentración de la tierra a 2021; Reducir el margen de intermediación en productos alimenticios a 2021: Mejorar el índice de intercambio [42].

Todas estas metas están encaminadas al aspecto agroambiental respeto a los derechos de la naturaleza y seguridad alimentaria.

Estudio de caso: Ordenanzas del Gobierno Autónomo Descentralizado Municipal de Francisco de Orellana, 2018, 2019 y 2020 (Tabla 2) [40].

\subsection{Discusión}

De la investigación realizada se verifica que, desde la vigencia de la Ley Orgánica para la Planificación Integral de la Circunscripción territorial especial Amazónica, aprobada por la Asamblea Nacional del Ecuador, publicada en el Registro Oficial Suplemento 245 de fecha 21 de mayo de 2018 [39], no se han aprobado en el Gobierno Autónomo Descentralizado Municipal de Francisco de Orellana ordenanzas relacionadas con el aspecto agroambiental (Tabla 2) [40], por lo que no existe un cumplimiento de las disposiciones agroambientales de la Circunscripción Territorial Especial Amazónica, instrumentos internacionales y disposiciones regionales y nacionales, sobre la materia.

\section{Conclusiones}

Los referentes legislativos en materia agroambiental analizados fueron la Constitución de la República del Ecuador 2008, Ley de Fomento y Desarrollo Agropecuario 1979, Código Orgánico de Organización Territorial, Autonomía y Descentralización 2010, Ley 


\section{Table 2}

Recursos bibliográficos consultados para el análisis de la legis/ación agroambiental municipal del Gobierno Autónomo Descentralizado Municipal de Francisco de Orellana, desde la entrada en vigencia de la Ley Orgánica para la Planificación Integral de la Circunscripción Territorial Especial Amazónica (Ordenanzas de los años 2018, 2019, 2020) [40].

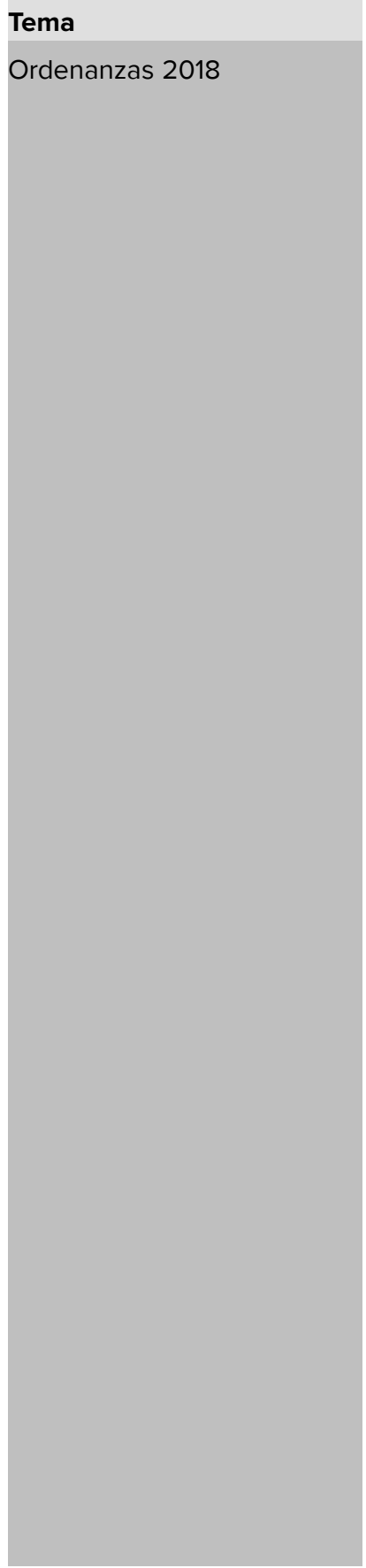

\section{Fuente}

-Ordenanza Numero 007: Ordenanza que regula el procedimiento para la legalización de asentamientos humanos de hecho y consolidados ubicados en el cantón Francisco de Orellana, de la Provincia de Orellana. -Ordenanza Numero 009: Ordenanza que declara de propiedad horizontal el bien inmueble, lote de terreno urbano signado con el Nro. 38, manzana Nro. 3 zona 2, ubicado en la calle Ambato entre Río Coca y Río Suno, barrio 'Paraíso Amazónico', ciudad de Puerto Francisco de Orellana, cantón Francisco de Orellana, Provincia de Orellana. - Ordenanza Numero 010: Ordenanza que declara de propiedad horizontal el bien inmueble, lote de terreno urbano signado con el Nro. 10-A, manzana Nro. D-5, ubicado en la calle Cuenca y 6 de Diciembre esquina del barrio 'Central', ciudad de Puerto Francisco de Orellana, cantón Francisco de Orellana, Provincia de Orellana.

- Ordenanza Numero 011: Ordenanza que contiene la Segunda reforma a la ordenanza que contiene el reglamento orgánico de gestión organizacional por procesos del Gobierno Autónomo Descentralizado Municipal Francisco de Orellana.

- Ordenanza Numero 012: Ordenanza que contiene la Primera reforma a la ordenanza que contiene el manual de descripción, valoración y clasificación de puestos y régimen remunerativo del Gobierno Autónomo Descentralizado Municipal Francisco de Orellana.

- Ordenanza Numero 013: Ordenanza que contiene la Primera reforma a la ordenanza que declara de propiedad horizontal el bien inmueble, lote de terreno Nro. 1-B, manzana Nro. 1, ubicado en la avenida 9 de Octubre y calle Jatuncocha, del barrio 'Los Rosales', cantón Francisco de Orellana, Provincia de Orellana.

-Ordenanza Numero 014: Ordenanza que declara de propiedad horizontal el bien inmueble, lote de terreno urbano signado con el Nro. 224, manzana Nro. 33, ubicado en la calle 'A' y 'L' (esquina), sector modelo ecológico; lotización 'El Recreo'; barrio 'El Moretal', ciudad de Puerto Francisco de Orellana, cantón Francisco de Orellana, Provincia de Orellana.

- Ordenanza Numero 015: Ordenanza de remisión de intereses, multas y recargos derivados de obligaciones tributarias, no tributarias y de servicios básicos, administrados por el Gobierno Autónomo Descentralizado Municipal Francisco de Orellana, y sus empresas amparadas en la Ley Orgánica de Empresas Públicas, Agencias, Instituciones y Entidades Adscritas, en el cantón Francisco de Orellana. - Ordenanza Numero 016: Ordenanza que declara de propiedad horizontal el bien inmueble, lote de terreno urbano, signado con el Nro. 4, manzana Nro. D2, ubicado en la calle Amazonas y Julio Llori, barrio 'Julio Llori', ciudad de Puerto Francisco de Orellana, cantón Francisco de Orellana, Provincia de Orellana, de propiedad del ciudadano, Hugo Isidro Tinizaray Ortega con cédula de ciudadanía Nro. 1900100171.

- Ordenanza Numero 017: Reforma a la Ordenanza que regula a Gestión de los Servicios de prevención, socorro y extinción de incendios en el catón de Francisco de Orellana. 
Table 2

Continued.

\begin{tabular}{|c|c|}
\hline Tema & Fuente \\
\hline Ordenanzas 2019 & 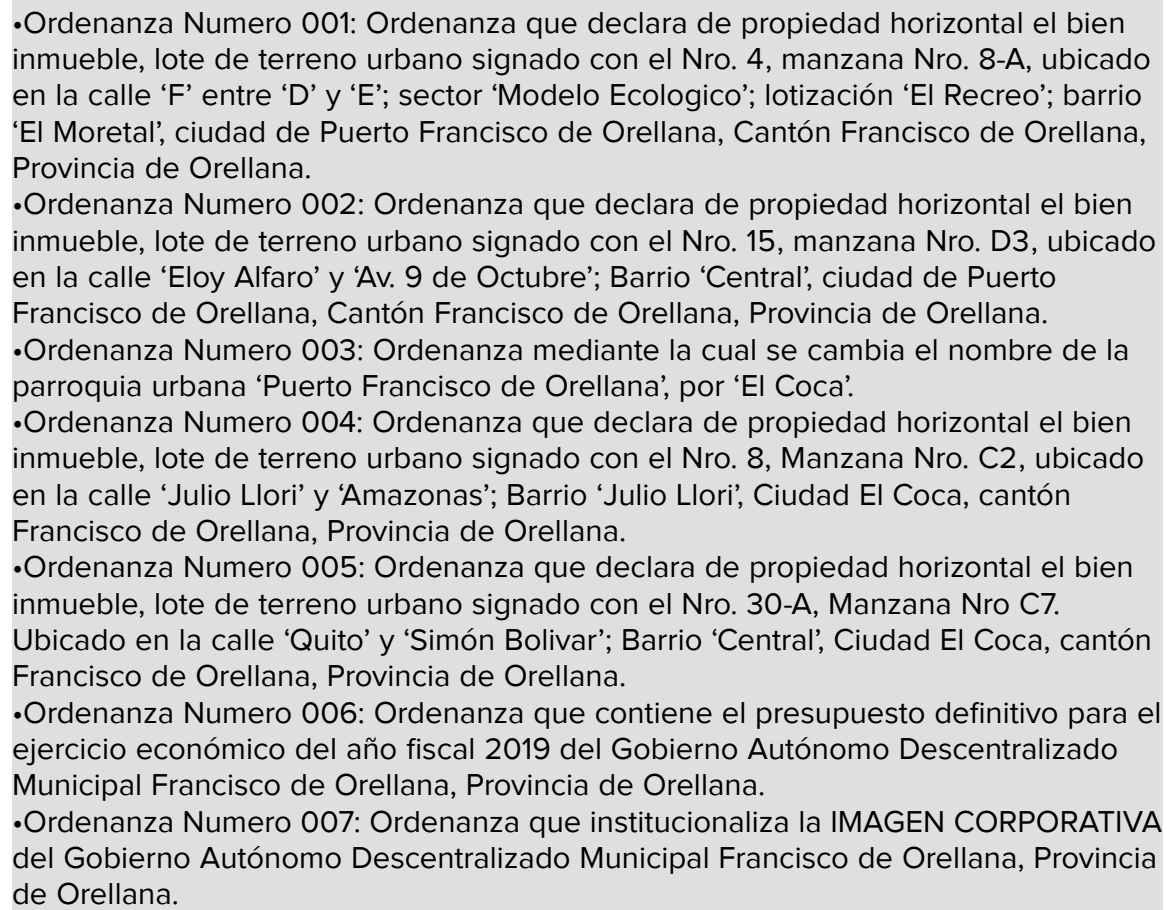 \\
\hline & - No existen Ordenanzas por el momento. \\
\hline
\end{tabular}

Especial Amazónica 2018, donde se evidencia la falta de aplicación de la normativa agroambiental.

La Ley Orgánica para la Planificación Integral de la Circunscripción Territorial Especial Amazónica 2018, no ha logrado articular y coordinar desde su vigencia la implementación de proyectos regionales de la Circunscripción

Territorial Especial Amazónica, así mismo no ha logrado articular proyectos Provinciales, y de los Gobiernos Autónomos Descentralizados Cantonales y Parroquiales Rurales.

La Falta de iniciativas de la ciudadanía, la pasividad de los actores políticos, la inequidad en la distribución de recursos para proyectos agroambientales, son aspectos que deben superarse para lograr el cumplimiento en la práctica de lo establecido en los instrumentos internacionales ratificados por el Ecuador, Constitución de la República del Ecuador, Ley de Fomento y Desarrollo Agropecuario, Código Orgánico de Organización Territorial, Autonomía y Descentralización, Ley Orgánica de Tierras Rurales y Territorios Ancestrales, Código Orgánico del Ambiente, Ley Orgánica para la Planificación Integral de la Circunscripción Territorial Especial Amazónica.

La implementación de ordenanzas en materia agroambiental, es un tema pendiente para el Gobierno Autónomo Descentralizado Municipal de Francisco de Orellana, existe 
el marco legal nacional, regional y de la Circunscripción Territorial Especial Amazónica apropiado para cristalizar ordenanzas encaminadas a solucionar los problemas agroambientales, garantizando el derecho a un ambiente sano y ecológicamente equilibrado garantizando la seguridad alimentaria.

\section{Agradecimientos}

Los autores expresamos nuestro agradecimiento a las siguientes Instituciones de Educación Superior que ha facilitado nuestro trabajo investigativo:

1. Escuela Superior Politécnica de Chimborazo, Sede Orellana, El Coca, OrellanaEcuador.

2. Universidad Andina Simón Bolívar, Sede Central, Sucre-Bolivia.

3. Universidad Técnica Particular de Loja, Loja-Ecuador

\section{References}

[1] Brañez R. Manual de derecho ambiental mexicano. 2nd edition. México: Fundación Mexicana para la Educación Ambiental; 2000.

[2] Escudero, JCO. La protección de la biodiversidad en el derecho ambiental mexicano: un análisis de la legislación desde el enfoque de especies amenazadas y su hábitat crítico. Boletín mexicano de derecho comparado. 2016;49(147): 347-371.

[3] Suárez F, Oñate JJ, Malo JE, Peco BEGOÑA. Las políticas agroambientales y de conservación de la naturaleza en España. Economía Agraria. 1997;179:267-296.

[4] Sánchez EJG, Vilela AM. La Agricultura de Conservación en la legislación agroambiental española. Agricultura: Revista agropecuaria. 2005;(878): 718- 724.

[5] Decreto Legislativo Numero 1 de fecha 7 de abril de 1932, Registro Oficial Numero 142, Ley de Adjudicación de tierras de comunidad a indígenas.

[6] López B, Alberto. Las Reformas Agrarias y Políticas Agrícolas en el Ecuador. Coyunturaisip. 2019 October 26. Disponible en: https://coyunturaisip.wordpress. com/2019/10/26/las-reformasagrarias-y-politica-agricola-en-el-ecuador/

[7] Pallares M. 50 años del gran cambio en el campo. Especiales.elcomercio. 2014. Disponible en: https://especiales.elcomercio.com/planeta-ideas/ideas/ 7-diciembre-2014/50-anos-grancambio-campo

[8] Morocho-Cabrera K. Insuficiencia de la Ley de Desarrollo Agrario en cuanto al control de actividades agrarias de los extranjeros en el Ecuador [Tesis de pregrado]. Loja: UNL; 2011. 
[9] Bedón-Garzón R. Legislación ambiental. Tomo I: Marco legal. 2017. Disponible en: http://ebookcentral.proquest.com

[10] Decreto Supremo 1480, del 11 de julio de 1964 publicada mediante Registro Oficial Numero 297 de fecha 23 de julio de 1964, ley de Reforma Agraria y Colonización.

[11] Decreto Supremo 3051 publicada en el Registro Oficial 342 de 28 de septiembre de 1964, Ley de tierras Baldías y Colonización.

[12] Decreto Supremo 373 y publicación en el Registro Oficial número 54, de fecha 7 de septiembre de 1970, Ley de Abolición del trabajo precario en la Agricultura.

[13] Decreto Supremo Numero 918 de fecha 21 de junio de 1971, publicada mediante Registro Oficial Numero 253 de fecha 25 de junio de 1971, Ley de Procedimiento Agrario.

[14] Decreto Supremo Numero 962 de fecha 30 de junio de 1971 se promulgo en el Registro Oficial Numero 259 de fecha 5 de julio de 1971 la Ley de Fomento Agropecuario y Forestal.

[15] Decreto Supremo 196, promulgada en el Registro Oficial Numero 2 de fecha 17 de febrero de 1972 se expidió la Ley Especial para Adjudicación de Tierras Baldías en la Amazonía.

[16] La Ley de Hidrocarburos fue codificada en el año 1978 mediante Decreto Supremo Numero 2967 publicada en el Registro Oficial Numero 711 de fecha 15 de noviembre de 1978.

[17] Decreto Supremo $N^{\circ} 374$, publicado en el Registro Oficial $N^{\circ} 97$ de 31 de mayo de 1976, Ley de Prevención y Control de la Contaminación Ambiental.

[18] Decreto Supremo 3289 publicado en el Registro Oficial 792 de fecha 15 de marzo de 1979, Ley de Fomento y Desarrollo Agropecuario.

[19] Mediante Registro Oficial No. 569 de 1 de Septiembre de 1983, se publicó la reforma a la Constitución de la República del Ecuador publicada en el Registro Oficial el 27 de marzo de 1979 que estuvo vigente desde el 10 de agosto de 1979.

[20] Registro Oficial número 461 de fecha 14 de junio de 1994 se publicó la Ley de Desarrollo Agrario

[21] Registro Oficial número 504 de fecha 15 de agosto de 1994, Ley Reformatoria a la Ley de Desarrollo Agrario.

[22] Asamblea Nacional Constituyente de la República del Ecuador. Constitución Política de la República del Ecuador. Riobamba-Chimborazo-Ecuador: Corporación de Estudios y Publicaciones; 1998.

[23] Congreso Nacional de la República del Ecuador, Registro Oficial número 245, de fecha 30 de julio de 1999, Ley de Gestión Ambiental.

[24] Decreto Ejecutivo N 3516 publicado en el Registro Oficial Suplemento 2 de 31 de marzo de 2003. 
[25] Texto Unificado de Legislación Ambiental Secundaria.

[26] Congreso Nacional de la República del Ecuador, Ley Forestal y de Conservación de Áreas Naturales y Vida Silvestre. Publicada en el Registro Oficial Suplemento No. 418 de 10 de septiembre de 2004.

[27] El portal del derecho ambiental. Ecolex. 2014. Disponible en: https://www.ecolex.org/ es/details/legislation/mandato-constituyente-no-16-programa-de-soberaniaalimentaria-lex-

[28] Asamblea Nacional Constituyente del Ecuador. Constitución de la República del Ecuador. 2008.

[29] Pozo E, Jiménez J, Chávez M, Chamba D. Legislación ambiental, regionalización y presupuesto. Ley orgánica de planificación integral de la circunscripción territorial especial amazónica. Iustitia Socialis. 2020;5:73-90.

[30] Asamblea Nacional de la Republica del Ecuador, Ley de Minería, Aprobada el 26 de enero de 2009 y publicada en el Registro Oficial No. 517 de jueves 29 de enero de 2009.

[31] Reglamento Ambiental de Actividades Mineras Expedido mediante Decreto Ejecutivo No. 121 de 04 de noviembre de 2009, publicado en el Registro Oficial No. 67 de 16 de noviembre de 2009.

[32] Código Orgánico de Organización Territorial Autonomía y Descentralización (COOTAD), publicado en el Registro Oficial Suplemento 303 de fecha 19 de octubre de 2010.

[33] Reglamento Ambiental de Actividades Mineras, expedido mediante Acuerdo Ministerial No. 37 publicado en el Registro Oficial Suplemento No. 213 de 27 de marzo de 2014.

[34] Ley Orgánica de Régimen Especial de la Provincia de Galápagos Publicada en el Registro Oficial Suplemento No. 520 de 11 de junio de 2015.

[35] Reglamento a la Ley de Régimen Especial de la Provincia de Galápagos Publicado en el Registro Oficial Suplemento No. 989 de 21 de abril de 2017.

[36] Ordenanza Provincial No. 001- CGREG-2015, Publicada en el Registro Oficial Suplemento No. 550 de 5 de abril de 2016, que establece el Plan para el Desarrollo Sustentable y Ordenamiento de la Provincia de Galápagos.

[37] Asamblea Nacional de la Republica del Ecuador, Registro Oficial Suplemento 711 de fecha 14 de marzo del 2016, se publicó la Ley Orgánica de Tierras Rurales y Territorios Ancestrales.

[38] FAO Legal Office. Ley orgánica de tierras rurales y territorios ancestrales. 2016. Disponible en: https://www.landportal.org/fr/library/resources/lexfaoc166211/ ley-org\{\%\}C3\{\%\}A1nica-de-tierras-rurales-y-territorios-ancestrales.

[39] Asamblea nacional de la republica del ecuador, registro oficial número 983 de 12 de abril del 2017, Código Orgánico del Ambiente. 
[40] Ley orgánica para la planificación integral de la circunscripción territorial especial amazónica, aprobada por la asamblea nacional del ecuador, publicado en el registro oficial suplemento 245 de fecha 21 de mayo de 2018.

[41] Gobierno Autónomo Descentralizado Municipal de Francisco de Orellana: Marco legal. Orellana. 2020. Disponible en: https://www.orellana.gob.ec/index.php/es/ component/content/article?id=123\&ltemid=437

[42] Plan de desarrollo y ordenamiento territorial del gobierno autónomo descentralizado municipal de francisco de orellana: Marco legal. 2020. Disponible en: https:// docplayer.es/77993047-Plan-de-desarrollo-y-ordenamiento-territorial-gadmfo.html

[43] Senplades. Plan Nacional de Desarrollo 2017-2021-Toda una vida. Quito; 2017. 